\title{
Paper
}

\section{Study on surface modification of paper friction material by optimization design of clutch disk construction equipment for automobile AT}

\author{
EIJI TOMA* ${ }^{* \dagger}$ Member \\ (Received October 11, 2017, revised February 07, 2018)
}

\begin{abstract}
Automatic transmission mechanism of automobiles has progressed especially in passenger cars the ratio of AT vehicles has become extremely large. As a result, the production quantity of clutch discs, which is one of the parts of the transmission mechanism, is also increasing, and parts manufacturers pay great effort to secure production volume and quality. A lot of parts to transmit power are incorporated in the automatic transmission inside of the car. In the clutch disc, there are various sizes and shapes according to specifications such as transmission torque. In the clutch disc which is the object of this research, a friction material made of special paper as a base material is adhered to both sides of a base material (iron type sheet metal) grooving processing for improving cooling efficiency is done on the surface of the friction material There. Since the quality of the disc directly affects the driving performance of the car, the quality of the friction surface is strictly controlled, in particular. The technical problem of a wet process clutch disc (DISC) having an important function about shifting is securing of stability of the power transmission torque in the catalytic action of shifting performance gain and DISC aspect each other automatic. That stabilization of the DISC board thickness precision controls in particular the change of the skin friction coefficient and reduces a shock phenomenon at the time of the shifting; have technical grounds. In this research, we designed the method of construction equipment which improved quality and productivity of DISC.
\end{abstract}

Keywords: Automatic transmission (AT), Power transmission, Clutch disc, Strength, Bearing selection, Tribology

\section{Introduction}

Automatic transmission mechanism of automobiles has progressed especially in passenger cars the ratio of AT vehicles has become extremely large. As a result, the production quantity of clutch discs, which is one of the parts of the transmission mechanism, is also increasing, and parts manufacturers pay great effort to secure production volume and quality. As shown in Fig. 1, a lot of parts to transmit power are incorporated in the automatic transmission inside of the car. Since the quality of the disc directly affects the driving performance of the car, the quality of the friction surface is strictly controlled, in particular.

The technical problem of a wet process clutch disc (DISC) having an important function about shifting is securing of stability of the power transmission torque in the catalytic action of shifting performance gain and DISC aspect each other automatic. In the clutch disc, there are various sizes and shapes according to specifications such as transmission torque[1].

In the clutch disc which is the object of this research, a friction material made of special paper as a base material is adhered to both sides of a base material (iron type

\footnotetext{
* Corresponding Author: toma-e@ @suruoka-nct.ac.jp

† National Institute of Technology, Tsuruoka College

104 Sawada, Inooka, Tsuruoka, Yamagata 997-8511, Japan
}

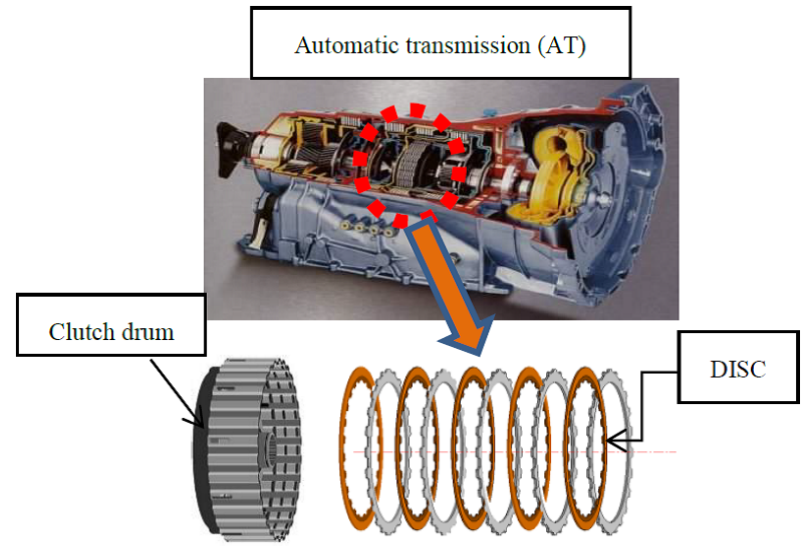

Figure 1: Appearance of clutch disc

sheet metal) grooving processing for improving cooling efficiency is done on the surface of the friction material There. That stabilization of the DISC board thickness precision controls in particular the change of the skin friction coefficient and reduces a shock phenomenon at the time of the shifting; have technical grounds[3].

In DISC production process, oil pressure heat board "Press-type" sizing process equipment (Fig. 2) is generally adopted. Problems of this method of construction equipment are that a shape change of the hot plate has an influ- 


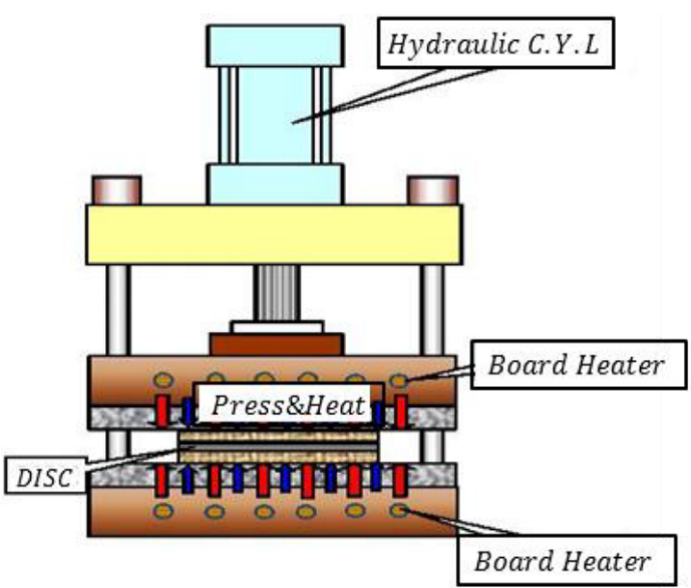

Figure 2: "Press-type" sizing process model

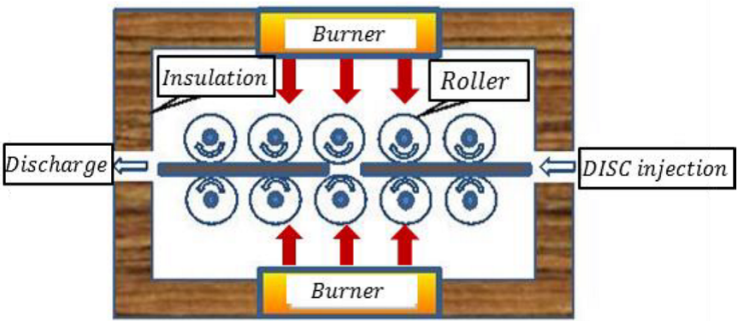

Figure 3: “Roll-type” sizing process model

ence on the fluctuation of the DISC plate thickness accuracy. We designed "Roll-type" sizing method of construction equipment" (Fig. 3) for improving of the DISC plate thickness accuracy in this research. By the practice of the machine element design, we realized improvement and stabilization of the DISC plate thickness accuracy[2].

\section{Technical problem}

Tribology is defined as "a surface exerting an interaction while performing relative motion and science technology related thereto". It is a field of engineering that comprehensively handles friction, lubrication, wear, and related phenomena. In the field of tribology technology, there is a technical basis that the improvement of the DISC plate thickness precision suppresses the rate of change of the dynamic friction coefficient $(\mu)$ on its surface and stabilizes the power transmission torque. In the hydraulic hot plate press type which is a conventional construction method as shown in Fig. 2, a change in shape of the hot plate with the passage of time influences the dispersion of the DISC plate thickness accuracy. Specifically, it was confirmed that the distortion of the hot plate over time under the high temperature heating condition $\left(400^{\circ} \mathrm{C} \pm 10{ }^{\circ} \mathrm{C}\right.$.) is a main cause of generating the dispersion $( \pm 0.05 \mathrm{~mm})$ of the DISC plate thickness accuracy[10].

Also, in the actual DISC production process, since the hot plate press method is a batch type production method, the production volume is limited by the tact time of the machine, so further productivity improvement cannot be expected.

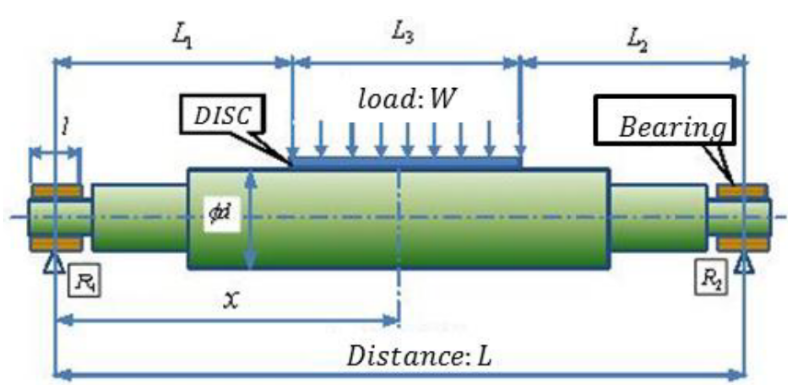

Figure 4: Load model of the roll

\section{Design of new construction method equipment}

As shown in Fig. 3, the heating roll rotation type structure was devised as new construction method equipment to which the mechanical element technology was applied for the purpose of reducing the shape change of the hot plate generated by the conventional construction method facility due to heat and load. The judgment criteria in the design and details of the specific mechanical element design will be described in detail below.

\subsection{Design of pressurization / heating method In} the hot plate press type of the conventional construction method facility, thermal distortion due to stress concentration occurs in the notch of the hot plate into which the electric heater is inserted. In order to reduce the shape change due to thermal strain of this hot plate, as shown in Fig. 3, we designed the upper and lower roll pressure type structure. The heating of the roll surface adopts a gas burner combustion formula, and in order to improve the thermal efficiency, the furnace wall is designed with a heat insulating structure. The thing to pay attention to when designing was design verification of the mechanical strength concerning deflection caused by heat of the upper and lower rolls.

In the design verification of mechanical strength, the theoretical backing that the roll strength calculation by heat and load is within the allowable stress relating to deflection is important. An example of calculation of roll strength is shown below.

3.1.1 Calculate the load of roll The load model of the roll is shown in Fig. 4.

The load $(\mathrm{P})$ per roll can be calculated from the following relational expression by back calculation from deflection.

$$
\begin{aligned}
\delta_{x}= & \frac{W \cdot X}{6 E \cdot I} \rightarrow W=\frac{\delta_{x} \cdot 6 E I}{X} \\
X= & \frac{\left(L_{3} x / L\right) \cdot\left(L_{2}+L_{3}\right)}{2} \\
& \cdot\left\{\frac{\left(L_{1}+L_{3}\right) \cdot\left(L+L_{2}+L_{3}\right)}{4}-\frac{L_{3}^{2}}{4}-x^{2}\right\} \\
& +\frac{\left(x-L_{1}\right)^{4}}{4}
\end{aligned}
$$

- Allowable limit value of deflection: $\delta_{x}=0.12$ [mm]

- Uniformly distributed load: $\mathrm{W}=\mathrm{P} / \mathrm{L}_{3}=31.7[\mathrm{~N} / \mathrm{mm}]$ 
E. Tома

Table 1: Characteristics comparison

\begin{tabular}{llll}
\hline \multicolumn{2}{c}{ Characteristic item } & Sliding bearing & Rolling bearing \\
\hline \multirow{2}{*}{ Mechanical property } & Load & $\begin{array}{l}\text { Suitable for impact load. } \\
\text { High allowable load. } \\
\text { Coefficient of static friction is big. } \\
\text { Coefficient of dynamic friction is equal. }\end{array}$ & $\begin{array}{l}\text { Inferior to impact load. } \\
\text { Low allowable load. } \\
\text { Coefficient of static friction is big. }\end{array}$ \\
& Life and damage & $\begin{array}{l}\text { Be infinite hydrodynamically. } \\
\text { Exfoliate in high load. }\end{array}$ & $\begin{array}{l}\text { Lifetime calculation by fatigue limit. } \\
\text { Seizure damage in the high speed. } \\
\text { Used performance }\end{array}$ \\
\cline { 3 - 4 } & Shock resistance & Advantage. & Disadvantage. \\
& Corrosion-resistant & Advantage. & Disadvantage. \\
\hline \multirow{2}{*}{ Economy } & Maintenance & Oil lubrication. & Grease lubrication. \\
& Cost & Easy to do a home brew and cheap. & Generally, cheap.
\end{tabular}

- Modulus of longitudinal elasticity:

$$
E=2.06 \times 10^{5}\left[\mathrm{~N} / \mathrm{mm}^{2}\right]
$$

- Roll diameter: $\phi \mathrm{d}=74.0[\mathrm{~mm}]$

- Cross sectional secondary moment:

- $I=\pi d^{4} / 64=147\left[\mathrm{~cm}^{4}\right]$

- DISC maximum diameter: $\mathrm{L}_{3}=\phi 210.0[\mathrm{~mm}]$

- Applied load of the sizing roll:

$$
P=W \cdot L_{3}=6,668[\mathrm{~N}]
$$

3.1.2 Roll maximum load $\left(P_{\max }\right)$, theoretical required power $\left(\boldsymbol{P}_{\boldsymbol{R}}\right) \quad$ Suppose that six rolls loaded maximum load,

- Roll maximum load:

$$
P_{\max }=6,667.5 \times 6=40,005[\mathrm{~N}]
$$

The design specifications of the new construction method facility are shown below.

- DISC conveyance speed: $\mathrm{v}_{\max }=6.5[\mathrm{~m} / \mathrm{min}]$

- DISC transit time: $\mathrm{t}=8.25$ [sec]

- Production tact time: $\mathrm{T}=2.0$ [sec/DISK]

- Roll turn peripheral velocity: $\mathrm{V}=0.11[\mathrm{~m} / \mathrm{s}]$

- Coefficient of rolling friction: $\mu=0.15$

The theoretical required power $\left(P_{R}\right)$ at the time of the maximum load of the roll is obtained by the following equation.

$$
P_{R}=\frac{W V}{102}=\frac{\mu F V}{102}=0.61[\mathrm{~kW}]
$$

3.2 Control of roll speed and choice of bearing The condition for ensuring plate thickness accuracy of DISC is to always stabilize the pressurization heating time and the clearance between the upper and lower rolls.

As a countermeasure against this, it is effective to control the synchronous rotation speed by the servo motor for rotating the roll. In addition, sliding bearings (bearing bushes) were selected due to superiority with respect to heat resistance and abrasion resistance of the end portion of the roll shaft.

The reason for selection is because of being superior in comparative abrasion quantity which is a property value of the bearing lifetime estimating and surface durability of the sliding surface.

3.2.1 Evaluation of bearing superiority Generally, bearings are classified roughly into sliding bearings and rolling bearings. Depending on each feature, it is necessary to select according to purpose. Rolling bearings use standard products made by bearing manufacturers, but sliding bearings use manufactured products according to the use of the equipment. Table 1 shows a comparison of characteristics between sliding bearings and rolling bearings.

(1) Compactification

Since the rolling bearing has a structure in which the rolling elements between the outer ring and the inner ring are in contact with each other, the outer diameter of the bearing is larger than the shaft diameter. Also, in rolling bearings, since it is subject to displacement to the axial center due to repeated stress, it is necessary to use a combination of a rolling bearing and a sliding bearing, and the structure becomes complicated. Therefore, sliding bearings enable compact sizing roll mounting intervals.

(2) Low cost

Rolling bearings are expensive because they require special steel as a material and require precise finishing work. Therefore, sliding bearings are more cost effective and more significant.

(3) Longer life due to lubrication

Rolling bearings are close to point contact in terms of structure, so they are weak against impact and not suitable for large loads. This is because Hertz's stress acts on the contact surface and flaking occurs on the raceway surface, so that the service life is shortened. On the other hand, the sliding bearing has a large contact area (projected area) with the shaft and high permissible surface pressure strength. Therefore, it is possible 


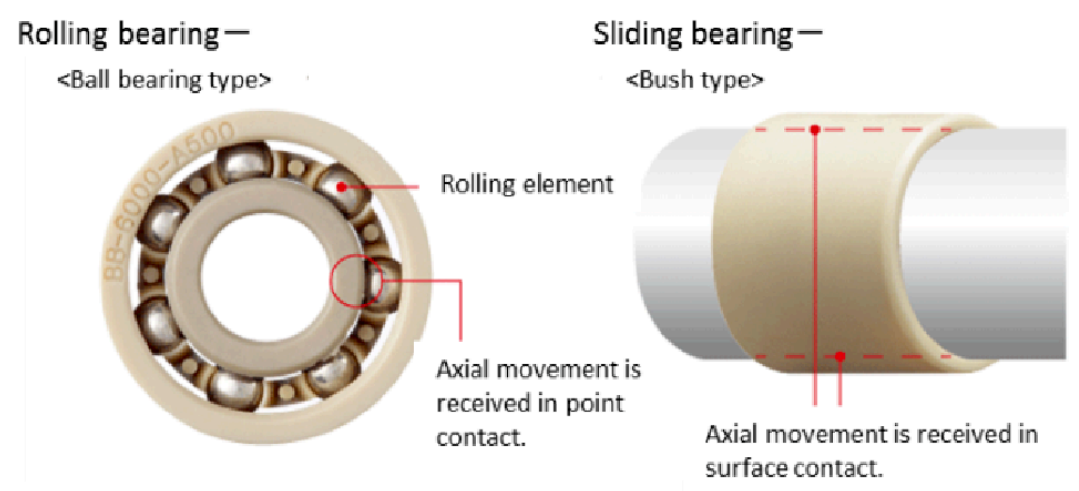

Figure 5: Structure comparison model

to withstand high load and to extend the service life by proper lubrication (in particular, intervention of oil film by liquid lubrication).

The structure comparison model of bearing is shown in Fig. 5.

3.2.2 Abrasion loss of the sliding bearing It is not yet established to theoretically estimate the abrasion loss of the bearing. In actual designs, empirical and experimental methods are mainly used to clarify the usage conditions as much as possible, and make judgments based on results such as experiments similar to the design specifications, model experiments, or actual experiments. It is important to build up as experience engineering that organizes the maintenance results during driving and feeds back to the next design. Normally, to estimate the abrasion loss, comparative abrasion quantity obtained from the experimental results is applied. Applying this comparative abrasion quantity makes it easy to estimate and calculate the abrasion loss, but care must be taken in adopting the coefficient.

That is to say, even with the same "PV value", the value of the comparative abrasion quantity largely varies depending on a number of factors such as speed difference, operating frequency, type and amount of lubrication, clearance with the shaft, material of the shaft and surface roughness. Therefore, the comparative abrasion quantity is used as a constant under a limited condition, and it is applied as a reference for comparison in design.

3.2.3 Life estimation of bearing The calculation result of the life estimation time up to the allowable abrasion loss based on the design specification of the "Roll - type equipment" is shown below.

\section{Design specification}

- Running form: continuous rotating

- Bearing materials: \#500SP5-SL101

- Bearing dimensions: $\phi 40 \times \phi 50 \times \mathrm{L} 30$ [mm]

- Shaft materials: S45C+Hard chromic plating

- Design Load: 3,430 [N]
- Bearing pressure: $P=286.2\left[\mathrm{~N} / \mathrm{cm}^{2}\right]$

- Axis number of revolutions: 28 [rpm]

- Sliding velocity: $\mathrm{V}=3.52[\mathrm{~m} / \mathrm{min}]$

- Bearing part temperature: $120\left[{ }^{\circ} \mathrm{C}\right]$

- Running frequency: 20h/day, continuous running

- Lubrication form: Grease lubrication , Periodical greasing

- Allowable abrasion loss: $\mathrm{W}=0.12$ [mm]

\section{Calculation of the life estimation time}

- Estimated sliding time: $\mathrm{T}[\mathrm{Hr}]$

- Comparative abrasion quantity: $K=5.6 \times 10^{-7}[\mathrm{~mm}]$

The life estimation time $(T)$ is obtained by the following equation.

$$
T=\frac{W}{K \cdot P \cdot V}=2,085[\mathrm{Hr}]
$$

However, the comparative abrasion quantity $(\mathrm{K})$ is the experimental value obtained from the bench test result at the bearing manufacturer. The bearing abrasion loss greatly depends on periodical greasing frequency and the ambient temperature. Therefore, in order to prolong the bearing life, it is effective to shorten the periodical greasing interval as much as possible and to cool the bearing sliding part as much as possible.

3.2.4 Surface pressure strength of sliding bearing The "PV (surface Pressure $\times$ peripheral Velocity) value" is used as a numerical value representing the limit of the load capacity of the bearing. As shown in Fig. 6, the bearing surface pressure $\mathrm{P}$ is a pressure acting on the bearing projection area, and is expressed by $\mathrm{P}=$ load / bearing projection area. As the value of $\mathrm{P}$ increases, the contact surface is damaged due to breakage of the oil film.

Therefore, it should not exceed the allowable value. As the peripheral velocity $\mathrm{V}$ of the shaft increases, the bearing temperature rises and the viscosity of the oil decreases markedly, so that the contact surface is seized. Therefore, 
Table 2: Technical and Economical result

\begin{tabular}{|c|c|c|}
\hline \multirow{2}{*}{ Product precision } & result & \multirow[t]{2}{*}{$\begin{array}{l}\text { Economical result } \\
\text { Cost (C) Delivery (D) }\end{array}$} \\
\hline & Power transmission performance & \\
\hline DISC thickness fluctuation & Change rate for coefficient of dynamic & Laborsaving by the productivity improvement \\
\hline Reduce it from $\pm 0.05[\mathrm{~mm}]$ to $\pm 0.02[\mathrm{~mm}]$ & Be controlled from $8 \%$ to $5 \%$ & $15 \%$ of labors reduction \\
\hline Securing of stable quality & Improvement of the transfer torque & Improvement benefit by cost reduction \\
\hline
\end{tabular}

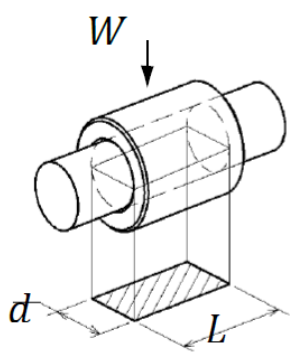

Figure 6: Bearing surface pressure and projected area

it is necessary to properly select the bearing material, lubricating oil and lubrication method, with the PV value as the heat generation limit value of the bearing. The PV value is defined as the product of the bearing surface pressure $\mathrm{P}$ and the peripheral velocity $\mathrm{V}$ of the shaft and is applied to determine the usable operating tolerance of the bearing.

The bearing surface pressure $\mathrm{P}$ is given by the expression (3).

$$
P=\frac{W}{d \cdot L}
$$

Bearing pressure: $P[\mathrm{MPa}]$, Bearing load: $\mathrm{W}\left(F_{r}\right)[\mathrm{N}]$, Shaft diameter: $d[\mathrm{~mm}]$, Bearing width: $L[\mathrm{~mm}]$

Axial peripheral velocity $\mathrm{V}$ is given by the expression (4).

$$
V=\pi \cdot d \cdot n \times 10^{-3}
$$

Axial peripheral velocity: $V[\mathrm{~m} / \mathrm{min}]$, Axis number of revolutions: $n[\mathrm{rpm}]$

\section{Conclusion}

Table 2 shows the evaluation results of quality, cost, and delivery time (QCD) for technical and economic outcomes in this research. As a technical result, DISC ensured stable quality of plate thickness accuracy, and power transmission torque improved. As an economic effect, by changing from the conventional batch production method to the continuous production method, productivity has been improved and cost reduction by labor saving has been achieved.

Figure 7 shows the evaluation results of the DISC friction performance characteristics against temperature in comparison with the construction method. From the results of the graph, it can be seen that a stable friction coefficient $(\mu)$ is obtained in the "Roll-type construction method" from low temperature to medium temperature, and high transmission performance is exhibited. Also, at high temperature, this excellent wide range is a major feature of the "Roll-type

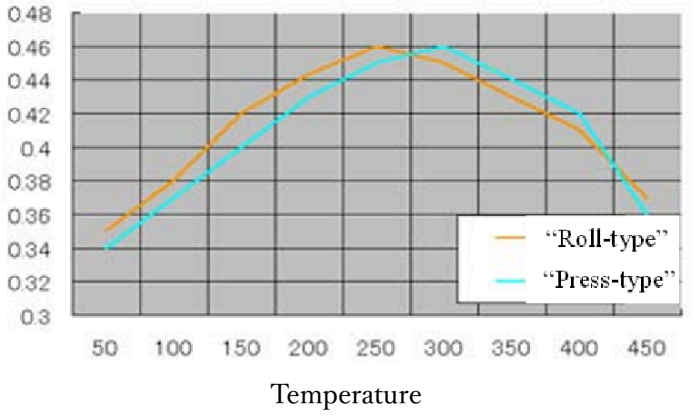

Figure 7: Friction performance characteristics

construction method" because it maintains a stable transmission performance although it is somewhat inferior to the "Press-type construction method"[4].

It is a continuous technical proposition to secure the stability of the initial shift performance of the automatic transmission. Stabilization of relative plate thickness accuracy of DISC is also a new technical problem in particular.

As the importance of protecting the global environment is increasing all over the world, automobile manufacturers are working on improving fuel economy in order to achieve reduction in $\mathrm{CO}_{2}$ emissions. Energy saving technology for environmental burden countermeasure in the automobile industry is an important science technology with high effectiveness.

As future technical trends, further research promotion in the field of tribology that can sufficiently reduce fuel consumption by reducing friction loss is necessary. Performance required for a clutch DISC as a product, such as improvement of shock (ride comfort) at the time of shifting by improvement of friction performance, improvement of fuel consumption by drag reduction (friction reduction) at the clutch OFF state, and so on[6].

While severe operating conditions are required for sliding parts, the technique of forming fine surface texturing has attracted attention as a method of improving tribology characteristics. At the same time, movements to promote theoretical systematization are also active think that technology that can solve problems to be solved, such as the influence of texture shape and scale, as well as possibility of great development[5].

Research on surface texturing for friction discs and paper friction materials has also been conducted in recent years. Typical examples are the formation of macro oil grooves as shown in Fig. 8, and by forming oil grooves of various shapes, sizes, and arrangements, it is possible to change 


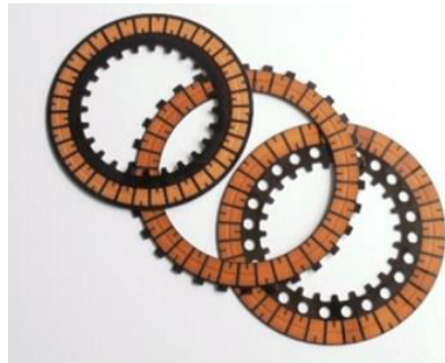

Figure 8: Oil groove shape of Friction disc for wet clutch

dynamic friction characteristics, heat resistance, Attempts have been made to control the sliding characteristics of wet type clutches, such as reduction of torque[6].

The development of "Segment DISC" capable of flexibly responding to these demands is proceeding. The advantage is that by realizing a highly flexible oil groove shape, it is expected to further improve the cooling efficiency and improve the friction performance[7].

As a method of forming a texture on the friction disc and the friction material surface the following method is currently used[9].

(1) Cutting: Machining grooves by machining.

(2) Embossing: Transfer grooves by pressing (mainly heat) using a mold.

(3) Segment (Extrusion): By punching and adhering frames in a segment shape, oil grooves corresponding to the shape of the frame are formed.

Particularly in the segment (3), when sticking the paper on the core board, a groove is formed by punching the paper into a predetermined shape. The segment grooves are high in mass productivity because each frame is completely cut off by the groove and becomes independent it can be incorporated in the process and has an effect of improving the yield of the paper[8].

Each of these methods currently used has advantages, but the paper friction material is a composite material containing various fibers, fillers, resins and the like, and the blended materials have different shapes, hardness, mechanical strength, fluffing of the processed surface, dropping of the material, reduction in the strength of the paper, and the like occur, resulting in a problem that it is impossible to perform clean processing. Paper friction materials have a plurality of required performances, and it is required to balance these performances.

That is to say, by forming a texture with a high aspect ratio on the surface of the paper friction material on the order of micrometers, there is a possibility that a new friction disc with improved friction characteristics can be developed without affecting other performances.

In the future research, we plan to design a device that can be applied to the Neo construction method (Roll-type construction method) developed in this research in order to improve the sheet thickness accuracy of the "Segment DISC".

\section{References}

[1] Y. Kimura, and H. Okabe, "Tribology outline", YOKENDO, pp.50-110, 1994.

[2] J. Okamoto and K. Nakayama, "Introduction to tribology friction, abrasion, the lubricant basics", SAIWAI SHOBO, pp.25-80, 2015.

[3] A. Haj-Fraj and F. Pfeiffer, "Modeling of Wet Clutches in Automatic Transmissions", The 2nd International Conference on Recent Advances in Mechatronics, pp.9-15, 1999.

[4] Y. Kato and N. Shibayama, "Structure of the automatic transmission, a function and wet process clutch", Tribologists, Vol.39, twelfth, pp.6-11, 1994.

[5] Y. Kato and R. Akasaka, "Friction properties analysis of wet process friction materials for automatic transmission", Tribologists, Vol.39, twelfth, pp.71-78, 1994.

[6] T. Miura and N. Sekine, "About friction properties of the automotive wet process clutch in the segment adhesion method", HONDA Technical Review, Vol.10, pp.142-149, 2011.

[7] T. Nakamura, "Energy saving of the car by the progress of the tribology technology", Tribologists, Vol.61, No.2, pp.3108, 2016.

[8] J. Takahashi, "Surface texture of power transmission clutch", Tribologists, Vol.48, No.9, pp.703-708, 2003.

[9] S. Sasaki, "Improvement of tribological characteristics by surface texturing", Surface technology, Vol.65, No.12, pp.568-572, 2014.

[10] T. Umehara, "Creation of functional surface for improving tribological characteristics", J. Vac. Soc. Jpn., Vol.58, No.6, pp.125-250, 2015.

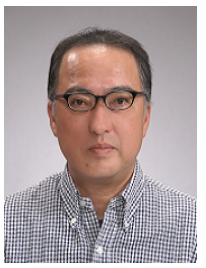

Toma Eiji (Member) He was born in Hokkaido, Japan, on December 17, 1959 When he was engaged as a manufacturing engineer at an automobile parts manufacturer, he acquired a "Professional Engineer (P.E.jp)" and "APEC engineer" in 2010, and is presently an professor at National Institute of Technology, Tsuruoka College. He has worked on research of the quality engineering. He is member of IIAE. 